\title{
Special issue: Development of renewable energy and smart grid
}

(C) Higher Education Press and Springer-Verlag Berlin Heidelberg 2017

Germany, as well as China, conducted a variety of activities in the past decade to reduce $\mathrm{CO}_{2}$ in national power supply and strived to move to more renewable generation. Due to geological differences in both countries, Germany established very fast a huge number of decentralized generation units from wind energy and photovoltaic. Judging from a technical point of view, these types of generation are highly fluctuating and not easily able to follow the power demand in the system minute by minute. Besides developing power generation from wind and photovoltaic, China made much more efforts in using its hydro power resources, wind energy, and photovoltaic. However, to develop renewable energy, China is now facing more challenges on transferring the electricity generated by wind energy and photovoltaic from remote areas to load center areas. This special issue will deal with different aspects of the integration of renewable energy into the power system, showing mainly the German point of view.

In the first paper dealing with the "Integration of renewable energies, flexible loads and storages: Actual situation in German change of power system" the situation in German power grid will be described and compared with the situation in China. Based on this overall description of the situation in the German power grid, another paper will elaborate on the "Impact of renewable energies on the operation and economic situation of coal fired power stations: Actual situation of coal fired power stations in Germany". Due to the highly fluctuating characteristics of renewable generation from wind energy and photovoltaic, coal fired power stations have to cover the gap between the renewable generation and the load minute by minute to keep the frequency and the power supply stable. A lot of technical changes and improvements have to be done to increase the dynamic behavior of such power stations formerly designed as base- or intermediate-load unit ones. In line with the constantly increasing power supply costs, the third paper will expound "The German Energiewende and its roll-out of renewable energies: An economic perspective". Since the start of energy revolution in Germany about 15 years ago, the electricity price for private consumers has dramatically increased. Unfortunately, most of this increase was caused only by the guaranteed funding of generation from renewable sources. The additional costs future assets in the power grid, which will be necessary to stabilize the reliability of a power system with huge share of fluctuating renewable generation will come on top to the energy prices in the next decade. Therefore, this special edition will show the German point of view of upcoming "Possible role of power-to-heat and power-togas as flexible loads in German medium voltage networks", as well as the "Possible role of "power-tovehicle and vehicle-to-grid as storages and flexible loads in the German 110 kV distribution grid." Another technical paper will discuss the "Influence of increasing numbers of RE-inverters on the power quality in the distribution grids: A PQ case study of a representative wind turbine and photovoltaic system".

The situation of renewable energy in Poland is quite different due to the economic and political conditions. The real prospects for a significant increase in the share of renewable energy in the energy mix will lie in the combustion of biofuels, biomass in particularly, and municipal waste in Poland. The paper "Real prospects for the development of power technologies based on renewable energy sources in Poland" analyzes this situation.

Wind energy as one of the most important renewable energy has been developed very fast in China. In order to take full advantage of the environmental benefits of wind energy, wind power forecasting has to be studied to overcome the troubles brought by the variable nature of wind. Two Power forecasting methods in the eighth paper are proposed which can achieve the proper 
feature set either by selecting the subsets or by transforming the original variables with specific combinations.

In recent years, increasing penetration of photovoltaic generations and replacement of internal combustion engine by electric vehicles have resulted in uncertainty factors in power systems in India. Authors discussed this problem and proposed a cumulant-based analytical method for such probabilistic load flow assessment in transmission and distribution systems. Another paper reviewed the stochastic optimization techniques for helping smart grid development including renewable energy resources. In the last paper authors discussed the management of electricity market with renewable energy in Germany.

We hope this special issue will give you interesting information on the development of renewable energy. We would like to thank all authors for their contribution to this special issue, and we are very grateful to all reviewers for their constructive comments, as well as the editorial staffs of the journal for the publication of this special issue.

\section{Guest Editors}

Prof. Dr. Harald SCHWARZ

Brandenburg University of Technology Cottbus-Senftenberg, Germany

E-mail: harald.schwarz@b-tu.de

Prof. Dr. Xiaoshu CAI

University of Shanghai for Science \& Technology, China

E-mail: caixs@usst.edu.cn

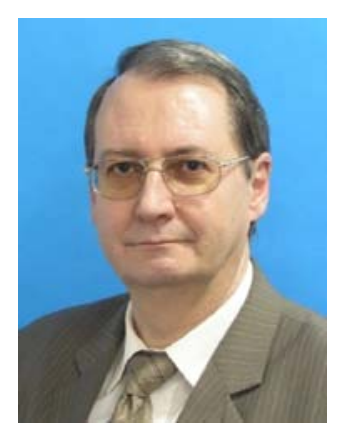

Prof. Dr.-Ing Harald SCHWARZ graduated as master of science in electrical engineering from Berlin University of Technology in 1982 and got his Ph.D. degree in electrical engineering from the University of Dortmund in 1986. From 1987 till 1995, he worked with ASEA BROWN BOVERI $(A B B)$ in large power transformers and high voltage switchgears before he joined Brandenburg University of Technology (BTU) in Cottbus as a full professor in energy distribution and high voltage engineering. In 1999, he commissioned one of the largest high voltage test fields at German universities. From 2002 to 2004, he was vice dean of Faculty for Mechanical, Electrical and Industrial Engineering and from 2004 to 2014, he was managing director of CEBra - Center for Energy Technology Brandenburg at BTU Cottbus, a central scientific research center under direct responsibility of the university president. In 2014, he established the Power System Simulation Center, which is unique at German university. Based on the university central campus with its peak load of $2.5 \mathrm{MW}$, he actually built up a smart grid with battery, heat and gas storages, renewable and conventional generation, as well as flexible loads from power-to-gas, to-heat and to-vehicle. He is also the head of examination board of the International, English Taught MSc Programme Power Engineering, which is linked to more than 15 excellent universities throughout the world and offers dual degrees e.g. with universities in Shanghai and Taiwan in China, St. Petersburg and Poland. Prof. Schwarz is the guest professor at the University of Shanghai for Science and Technology (USST) and the professor of Honors at Shanghai University for Electric Power. In 2015, he was honored the professor of "Peter the Great" by St. Petersburg University of Technology and from Oct. 2013 to end of 2014 , he was a senator of the enlarged founding senate of BTU Cottbus-Senftenberg.

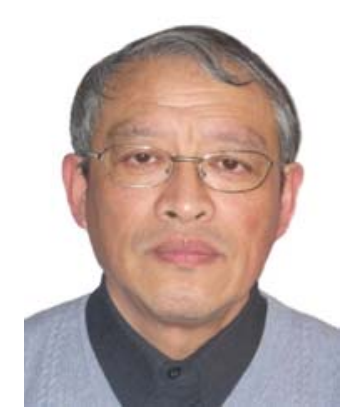

Prof. Dr. Xiaoshu CAI worked in a power plant from 1972 to 1978, then studied in Zhejiang University and received his Bachelor degree in 1982. From 1982 to 1985 , he worked in the Department of Steam Turbine in Shanghai Power Equipment Research Institute as an engineer. He received his Master and Ph.D. degrees in thermal power engineering from Shanghai Institute of Mechanical Engineering, respectively in 1988 and 1991. Since then he has worked in University of Shanghai for Science and Technology (USST) as an associate professor, professor, director of Graduate School, dean of the College of Power Engineering. His mainly research and interesting areas are thermal power engineering, renewable energy and measurement techniques for multi-phase flow, particle sizing, combustion and environmental monitoring. He has published more than 200 journal papers and been granted approximately 30 patents. 